\title{
Influence of Treatment against Decomposition and Water Absorption on Fiber Matrix Interfacial Shear Strength of Glass Fiber Reinforced PLA
}

by

\author{
Kazuto Tanaka*, Ayumi Inagaki** and Tsutao Katayama*
}

Glass Fiber Reinforced Plastics (GFRP) have been used for various applications such as automobiles, motorboats and so on. Since GFRP in which thermosetting resins are used as a matrix is difficult to recycle, thermoplastic resins superior in recyclability have been receiving attention. Especially, polylactic acid (PLA), which is plant-derived and biodegradable resin, has been receiving attention as an environmentally friendly material. When PLA is used as a matrix of FRP, it is necessary to suppress hydrolysis at the time of use as in ordinary petroleum-based plastics. Recently, a method to decrease the rate of decomposition of PLA has been developed by combining a decomposition inhibitor (Poly Methyl Methacrylate: PMMA) with PLA and annealing treatment. For a decomposition inhibitor PMMA, in which the methyl ester group protects the ester group of PLA, suppress the hydrolysis during use. By performing an annealing treatment, the degree of crystallization of PLA is increased and the progress of hydrolysis can be delayed. As described above, although PLA with higher resistance to hydrolysis have been developed, the mechanical properties of GFRP using PLA decomposition inhibitor as a matrix have not been clarified yet. In this study, single fiber pull-out tests were conducted by using GF/PLA model composites to clarify the influence of decomposition inhibitor and annealing treatment. Though the fiber/matrix interfacial shear strength was decreased by water absorption, the decomposition rate for GF/PLA with a decomposition inhibitor and annealing treatment was the lowest and showed excellent water resistance.

\section{Key words:}

Glass fiber reinforced plastics, Polylactic acid, Single fiber pull-out test, Model composites, Interfacial shear strength, Water absorption, decomposition inhibitor, Annealing treatment

\section{1 緒言}

ガラス繊維強化樹脂複合材料 (Glass Fiber Reinforced Plastics: GFRP) は, 自動車部材や船舶など様々な用途に 使用されてきた ${ }^{1), 2)}$. これらの GFRP ではマトリックス に熱硬化性樹脂を用いているため廃棄時の処理が問題 となっており ${ }^{3)}$, 4)，環境への負荷が低(樹脂をマトリッ クスに用いた GFRP の実用化が課題となっている.

この問題の解決策の一つとして, グリーンコンポジット

(Green Composites) といった生分解性樹脂を用い た ${ }^{5)}$ FRPが挙げられる. 中でもポリ乳酸（Polylactic Acid: PLA（Fig. 1））は，他の生分解性樹脂よりも高比強度，高 比剛性という特性を持つため, GFRPのマトリックスとして の応用が期待されている ${ }^{12), 13)}$. PLAは生分解性を有するも のの, 実使用中は従来の石油由来の高分子樹脂を用いた GFRP と同様の安定した物性を示すことが望まれるため, 実 使用中の加水分解は抑制する必要がある.

近年，PLA に分解抑制剂を配合して分解速度を抑制す
る方法が開発されている ${ }^{14)}$. 分解抑制剂として利用でき るポリメチルメタクリレート (Poly Methyl Methacrylate: PMMA (Fig. 1)) は, メチルエステル基が PLA のエステ ル基の酸素原子と水素結合を形成することで PLA のエス

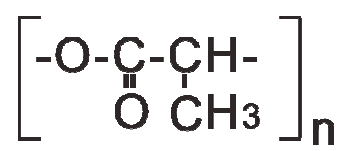

(a) PLA

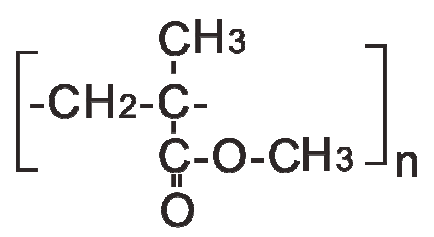

(b) PMMA

$\dagger$ 原稿受理 平成30年1月10日 Received Jan. 10,2018 C2018 The Society of Materials Science, Japan

* 正 会 員 同志社大学 生命医科学部医工学科 $\bar{\top} 610-0394$ 京田辺市多々羅都谷

Dept. of Biomed. Eng., Doshisha Univ., Tatara-miyakodani, Kyotanabe, 610-0394.

** 学生会員 同志社大学大学院 干610-0394 京田辺市多々羅都谷

Dept. of Biomed. Eng., Doshisha Univ., Tatara-miyakodani, Kyotanabe, 610-0394. 
テル基を保護し，使用中の加水分解を抑制することが可 能である. なお, 廃棄時には分解抑制剤のガラス転移温度 以上に加熱することで，PMMA の分子の運動性が高めら れ，エステル基による水素結合の拘束が解消され，分解 抑制効果が消失し，通常のポリ乳酸と同様の分解が進行 することになる ${ }^{14)}$. 他の分解抑制の手法としてはアニー リング処理がある。これにより PLA の結晶化度が高くな り，加水分解の進行を遅らせることが出来るという報告 もあり ${ }^{15)}$ ，PLA をマトリックスとした GFRPにおいても アニーリングによる加水分解の抑制が期待される.

繊維強化樹脂複合材料の引張試験において，吸水環境 下では積層板の引張強度が低下寸ること，それは，繊維 樹脂界面の弱化による層間強度低下が原因であることが 明らかにされてきた ${ }^{16)}$ 。筆者等は，吸水した水は，表面 の樹脂だけではなく繊維樹脂界面を優先的に浸透し, 繊

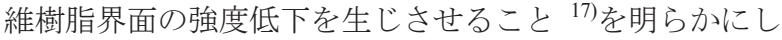
ており，複合材料の実環境下での信頼性確保のためには, 繊維樹脂界面特性の定量評価や界面破壊のメカニズムの 解明が重要である.

繊維と樹脂の界面強度に寄与寸る結合には化学結合と 物理的な結合が挙げられる ${ }^{18)}$ ，筆者等は，マトリックス 樹脂の収縮に起因した䋊維を締め付ける力，すなわち残 留応力が，纎維樹脂界面せん断強度に大きく影響を及ぼ すことを明らかにしており，化学結合だけでなく物理的 な締め付け圧の評価も重要となる ${ }^{19)}$.

そこで本研究では，ガラス繊維強化ポリ乳酸複合材 料のモデルコンポジットを用いて単䋊維引抜き試験を 実施し, 分解抑制剂である PMMA の配合やアニーリン グ処理が繊維樹脂界面せん断強度に及ぼす影響を明ら かにするとともに, 繊維樹脂界面せん断強度に及ぼす水 環境の影響を明らかにした。ここでは，樹脂単体の密度 測定，結晶化度測定および吸水試験を行うとともに，繊 維樹脂界面せん断強度に及ぼす再絶乾処理の影響や高 温保持の影響を明らかにすることで，水環境下における 繊維樹脂界面破壊のメカニズムを考察した。

\section{2 供試材および実験方法}

\section{$2 \cdot 1$ 供試材およびアニーリング条件}

本研究では, マトリックスに絶乾処理を行った PLA（浙 江海正生物材料，Revode190）と，PLA に分解抑制剂とし てPMMA を 5 wt.\%配合した樹脂（以後PLA+PMMA と示 す）のペレットとプレートを使用した。強化䋊維には, ガラス繊維平織物（日東紡績, 目付 $203 \mathrm{~g} / \mathrm{m}^{2}$ ) から取り出 した単繊維を使用した。

供試材や $2 \cdot 3$ 節に後述する単繊維引抜き試験片のア ニーリング処理は, $120^{\circ} \mathrm{C}$ に加熱した恒温槽に 5 分間保持 したのち，徐冷する処理としたＰLA と PLA+PMMA に アニーリング処理を行った樹脂をそれぞれ，APLA， APLA+PMMA と称す.

\section{$2 \cdot 2$ 樹脂単体の特性評価}

射出成形により作製した $15 \times 15 \times 2 （ \mathrm{~mm})$ の樹脂プ レートに対して，X 線回折装置（PANalytical，

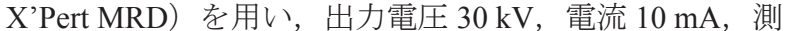
定範囲を $2 \theta=10 \sim 40 \circ の$ 条件で測定し, 式（1）を用い て結晶化度を算出した。

$$
X_{c}(\%)=\frac{I_{c}}{I_{c}+I_{a}} \times 100
$$

ここで， $X_{c}$ は結晶化度， $I_{c}$ は結晶性部分による散乱強度， $I_{a}$ は非結晶性部分による散乱強度である。

樹脂単体の比容積測定には，樹脂ペレットを用い，乾 式自動密度計（島津製作所，アキュピック 1330）により 測定した。

射出成形により作製した $25 \times 40 \times 2 （ \mathrm{~mm} ）$ の樹脂プ レートを用いて, 樹脂単体の吸水による重量増加や溶出 による重量損失を評価するため，気相中で吸水試験を 行った。絶乾状態の試験片重量 $W_{0}$ を測定し, $80{ }^{\circ} \mathrm{C}$, 相 対湿度 $100 \%$ に調湿したデシケータ内に入れ, 1 時間保持 した後, 表面の水分を拭き取った後に, 重量 $W$ を測定し た。また，重量測定後，試験片を $80^{\circ} \mathrm{C}$ ，相対湿度 $0 \%$ に調湿した恒温槽内に 1 時間入れることで, 再絶乾処理 を行い，試験片の重量 $W_{d}$ を測定した。吸水試験におけ る重量変化の概略図を Fig. 2 に示す. $W$ と $W_{0}$ の差が PLA が吸水した分の重量増加, $W_{0}$ と $W_{d}$ の差が PLA が加水分 解し重量低下した重量となる。重量増加率 $M_{1}$ と重量損 失率 $M_{2}$ を式 (2)，（3）より算出した.

$$
\begin{gathered}
M_{l}(\%)=\frac{W-W_{0}}{W_{0}} \times 100 \\
M_{2}(\%)=\frac{W_{0}-W_{d}}{W_{0}} \times 100
\end{gathered}
$$

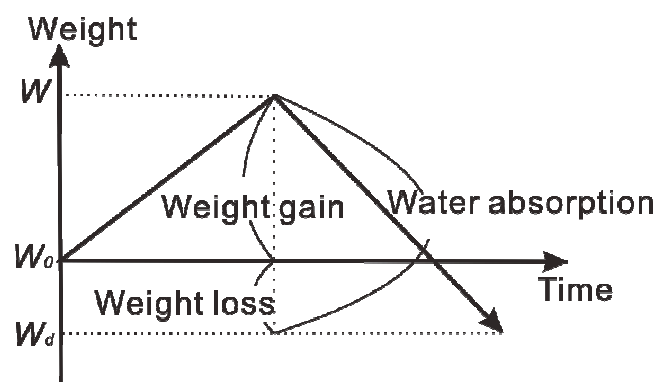

Fig.2 Schematic drawing of a water absorption test.

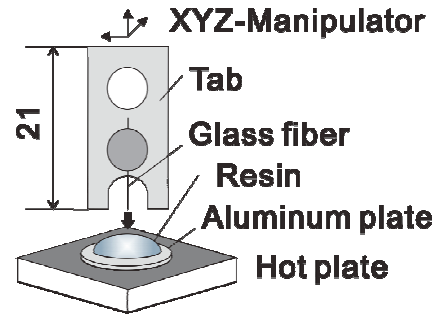

Fig. 3 Schematic drawing of a pull-out specimen. 


\section{$2 \cdot 3$ 単繊維引抜き試験}

単繊維引抜き試験片の作製時の概略図を Fig. 3 に示 す. $10 \mu \mathrm{m}$ 単位で移動可能なマニピュレータを操作するこ とで，ポリエステル製のタブに取り付けたガラス繊維一 本を， $220{ }^{\circ} \mathrm{C}$ に加熱したホットプレートの上のアルミニ ウムの円板上で溶融した樹脂ペレットに挿入し，空冷し て試験片を作製した．以後PLA を用いてこのように作製 した試験片を GF/PLA，PLA+PMMA を用いて作製した試 験片を GF/PLA+PMMA と称する。一部の試験片は $2 \cdot 1$ 節で示した条件でアニーリング処理を施した。以後,

GF/PLA, GF/PLA+PMMA にアニーリング処理を施した試 験片をそれぞれ GF/PLA，GF/APLA+PMMA と称する．以 上の 4 条件の試験片の一部は $2 \cdot 2$ 節で樹脂単体に適用し たのと同じ条件で吸水させた。以後，この試験片をWet と称し, 吸水させていない空中放置材を Dry と称する. なお，繊維樹脂界面強度特性に及ぼす再絶乾処理の影響 を明らかにするために GF/PLA に対しては再絶乾処理を 行った. 再絶乾処理方法は，2・2 節で樹脂単体で適用し た条件と同条件で行った. 以後, この試験片を Redry と称 する.

PLA と PLA+PMMA をマトリックスに用いたモデル コンポジットでは繊維樹脂界面特性に及ぼす試験片作製 時の高温保持の影響を明らかにするため，試験片作製時 に $220{ }^{\circ} \mathrm{C}$ に加熱したホットプレート上で溶融した樹脂に ガラス繊維を挿入したのち, 5 分間保持した試験片も作製 した. 以後, PLA, PLA+PMMA をマトリックスに用いて, 試験片作製時に高温保持した試験片を GF/HPLA， GF/HPLA+PMMA と称し, GF/HPLA の試験片の一部は上 記と同条件で吸水させた.

単繊維引抜き試験は，電磁力式微小試験機（島津製作 所，マイクロサーボ MMT-11N，最大荷重 $10 \mathrm{~N} ）$ を用い, 引張変位速度 $1.67 \times 10^{-6} \mathrm{~m} / \mathrm{s} \quad(0.1 \mathrm{~mm} / \mathrm{min})$ の変位制御下 で行った．単䋊維引抜き試験後，Fig. 4 に示すように走査 型電子顕微鏡（日本電子，JSM-6390L，SEM）を用いて観 察し，樹脂にガラス緎維が埋め込まれていた長さ $l$, 繊維 直径 $d$ を測定した。単繊維引抜き試験時の最大荷重 $F_{\text {max }}$ とこれらの值から，以下の式（4）を用いて繊維樹脂界面 せん断強度 $\tau$ を算出した。

$$
\tau=\frac{F_{\max }}{\pi d l}
$$

\section{3 実験結果と考察}

\section{$3 \cdot 1$ 樹脂単体の特性評価}

X 線回折装置を用いて求めた PLA, APLA, PLA+PMMA, APLA+PMMA の結晶化度を Fig. 5 に示す. PMMA の有無 では，結晶化度に差は見られないが，PLA，PLA+PMMA ともに，アニーリングを行っていない試験片に比べてア ニーリングを行った試験片は高い結晶化度を示した.

乾式自動密度計を用いて測定した密度測定結果を Fig. 6 に示寸. APLA が最も高い密度を示し, PLA,
APLA+PMMA，PLA+PMMA の順で低くなったＰMMA を配合することにより密度は低くなり, PLA, PLA+PMMA のいずれにおいてもアニーリングを施すことで密度は高 い值を示した。

吸水試験後に再絶乾処理することで得られた PLA, PLA+PMMA 樹脂単体の重量増加率と重量損失率を Table 1 に示す. いずれの試験片においても, 再絶乾処理 を行うと重量が低下し, 重量増加率と重量損失率はいず れも PLA よりも PLA+PMMA の方が低い值を示し, PMMA の配合により優れた耐加水分解特性を有すること がわかる。

\section{$3 \cdot 2$ 界面せん断強度に及ぼす水環境の影響}

単繊維引抜き試験により求めた GF/PLA，GF/APLA, GF/PLA+PMMA, GF/APLA+PMMA の Dry, Wet それぞれ における最大荷重と繊維の埋め込み長さの関係を Fig. 7 に示す. 式（3）により求めた Dry, Wet, Redry の繊維樹

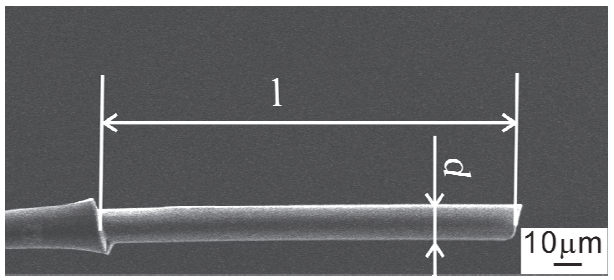

Fig. 4 SEM observation of a pull out specimen

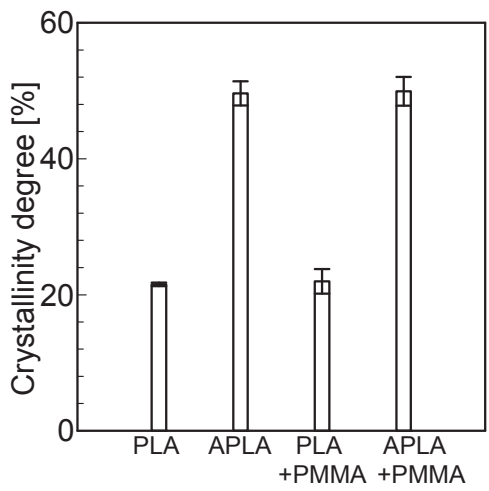

Fig. 5 Crystallinity degree for resins. $(\mathrm{N}=5$, mean \pm S. D. $)$

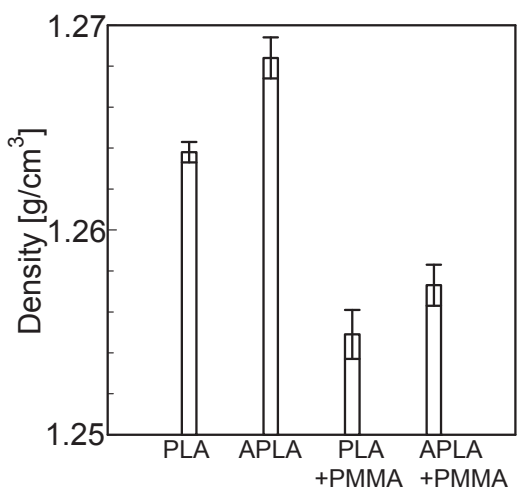

Fig. 6 Density for resins. $(\mathrm{N}=5$, mean \pm S. D. $)$ 
脂界面せん断強度を Fig. 8 に示す.いずれの試験片におい ても Wet が Dry よりも低い繊維樹脂界面せん断強度を示 し，GF/PLA においては Dry, Redry, Wet の順で䋊維樹脂 界面せん断強度が低い值を示し，再絶乾処理を行うと繊 維樹脂界面せん断強度が Wet よりも高くなり，回復する ことがわかる。

Fig.8 に示した各試験片の Dry の繊維樹脂界面せん断 強度を 100 として求めた Wet の繊維樹脂界面せん断強度 保持率を Fig. 9 に示寸。界面せん断強度の低下率は

\begin{tabular}{ccc} 
Table 1 & Weight loss rate and weight gain rate. \\
\hline Specimens & $\mathrm{M}_{1}$ & $\mathrm{M}_{2}$ \\
& Weight gain rate & Weight loss rate \\
& {$[\%]$} & {$[\%]$} \\
\hline PLA & 0.8 & 0.6 \\
\hline PLA+PMMA & 0.6 & 0.2 \\
\hline
\end{tabular}

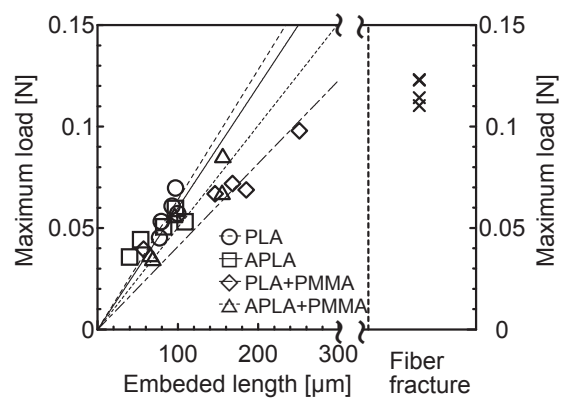

(a) Dry specimens

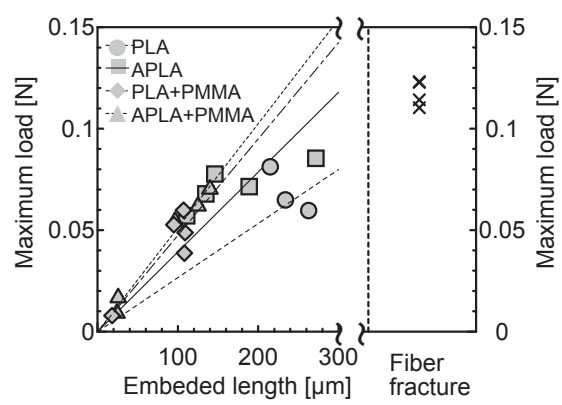

(b) Wet specimens

Fig. 7 Relationship between embedded fiber length and maximum load of the load displacement curves for GF/PLA, GF/APLA, GF/PLA+PMMA and GF/APLA+PMMA.

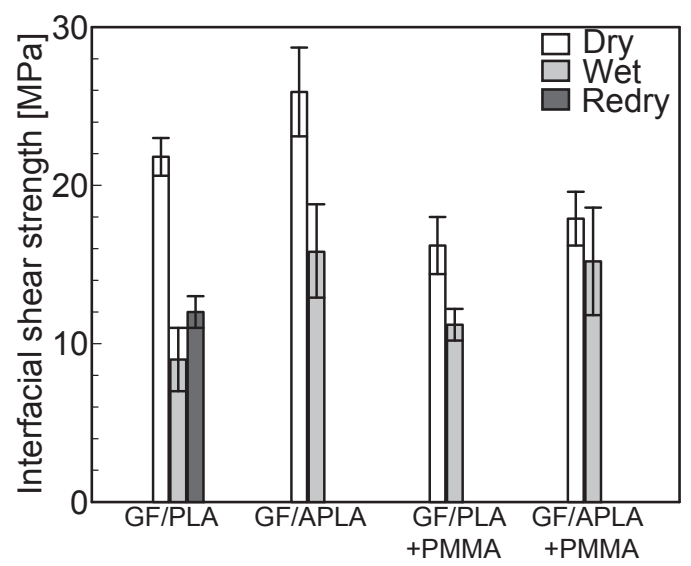

Fig. 8 Interfacial shear strength of Dry, Wet and Redry specimens.
GF/PLA , GF/PLA+PMMA , GF/APLA+PMMA , GF/APLA+PMMA の順でそれぞれ $59 \%, 38 \%, 31 \%, 15 \%$ となり, GF/APLA+PMMA が最も而水環境特性に優れて いることが分かる.

各Dryの条件下の試験片に対して Fig. 6に示した密度と Fig. 8 に示した繊維樹脂界面せん断強度の関係をグラフ 化して Fig. 10 に示す。密度が高いほど繊維樹脂界面せん 断強度が高い傾向を示している，筆者等は CF/PA の繊維 樹脂界面せん断強度評価において，樹脂の比容積が小さ い程（密度が高いほど）樹脂が繊維を締め付ける力が強 くなり，これにより繊維樹脂界面せん断強度が高くなる

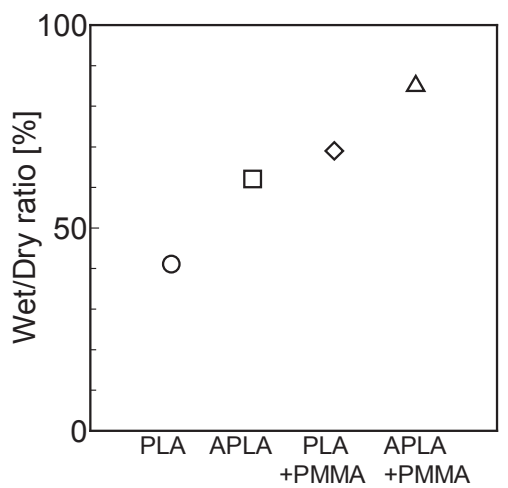

Fig. 9 Wet/Dry ratio for interfacial shear strength of GF/PLA.

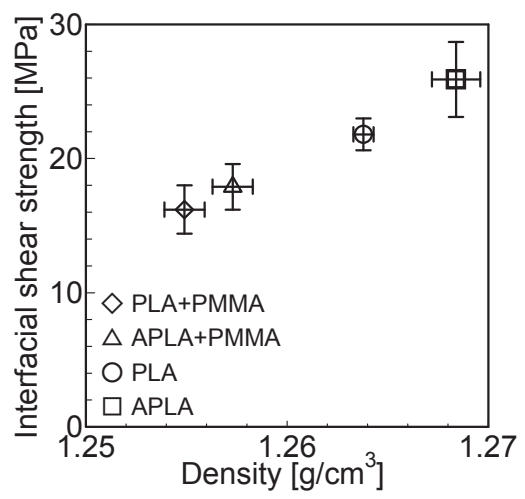

Fig. 10 Relationship between density and interfacial shear strength for Dry specimens.

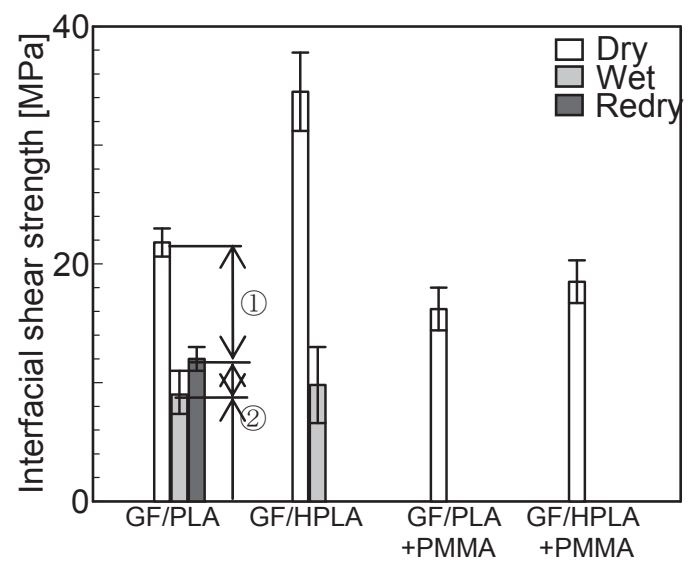

Fig. 11 Interfacial shear strength for heat treatment with extracted Fig. 8 . 
と報告している ${ }^{19)}$. 本研究において使用したPLA におい ても，密度と繊維樹脂界面せん断強度の大小関係が対応 しており，高い密度に起因して樹脂が緎維を締め付ける 力が高くなり，高い繊維樹脂界面せん断強度を示したも のと考えられる.

単繊維引抜き試験により求めた GF/HPLA, GF/HPLA+PMMA の䋊維樹脂界面せん断強度を Fig. 8 に 示した GF/PLA と GF/PLA+PMMA の結果と合わせて Fig. 11 に示す. GF/PLA, GF/PLA+PMMA どちらにおいて も試験片作製時に高温保持を行うと高い強度を示すこと が分かる。また，GF/HPLA と GF/HPLA+PMMAの強度向 上率を，高温保持を行っていない試験片を 100 とし，

Fig. 12 に示寸. 繊維樹脂界面せん断強度の向上率は GF/HPLA の方が GF/HPLA+PMMAよりも高い值を示した。

繊維強化樹脂複合材料において，繊維と樹脂の界面 強度に寄与する結合として, 化学結合, 物理的結合, アン カー効果などが挙げられ ${ }^{18)}$, 試験片作製時に樹脂が繊維 を締め付ける残留応力は，結合の種類によらず界面特性 に影響を及ぼすと考えられる、筆者等は, CF/PP の繊維樹 脂界面において，高温保持を行うと繊維樹脂界面で化学 結合が増加し, 繊維樹脂界面せん断強度が高くなること を明らかにしてきた ${ }^{20)}$ 。 また，ガラス表面には水が化学 吸着し，シラノール基が生成され ${ }^{21)}$ ，シラノール基はカ ルボニル基と Fig. 13 のように水素結合を行うことが報告 されている 22)，23)．以上のことより，試験片作製時の高温 保持によりガラス繊維表面のシラノール基と PLA のカル ボニル基の水素結合が促進され，繊維樹脂界面せん断 強度が高くなったと考えられる。GF/PLA+PMMA では， PMMA を配合していることにより，GF/PLA と比べて繊 維表面に存在する PLA の量が少なくなるため, 試験片作 製時の高温保持による化学結合の増加の寄与が少なく， GF/PLA+PMMA の強度向上率が GF/PLA よりも小さく なったと考えられる。

筆者等は CF/PA において，Wet と比べて Redry で繊維 樹脂界面せん断強度が回復した分が樹脂の比容積変化に 対応し，回復しなかった分が化学的な結合の劣化である ことを明らかにしてきた ${ }^{24)}$. 本研究で用いたPLA におい ては Redry 材では纎維樹脂界面せん断強度が回復したも のの Dry とは大きな差が見られた. Fig. 11 中に(1)で示す Redry と Dry の差が化学的な結合の消滅による強度低下, (2)に示す Wet から Redry に回復した分が樹脂の比容積変 化による強度低下であると考えられる。したがって, PLA においては吸水による樹脂の膨潤による比容積変化と比 べて，化学的な結合の劣化の方が大きく影響していると 考えられる.

GF/PLA と GF/HPLA の Dry において, GF/HPLA は GF/PLA よりも高い值を示していたが，それぞれの Wet の值に差はなかった。このことからも，GF/PLA において 吸水を行うと化学結合の劣化が起こり, 繊維樹脂界面せ ん断強度が低い值を示したと考えられる．以上のことよ

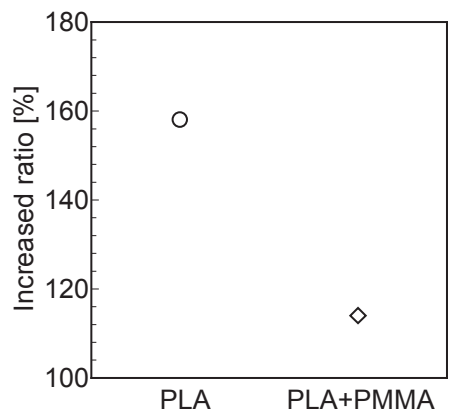

Fig. 12 Increased ratio for interfacial shear strength.

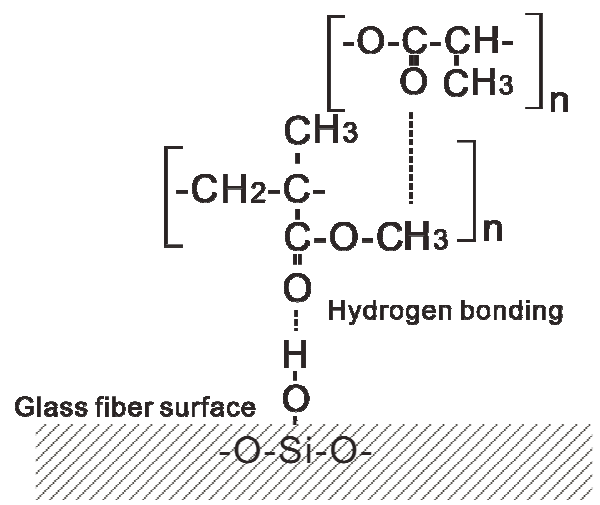

Fig. 13 Hydrogen bonding

り，吸水での繊維樹脂界面せん断強度の低下は化学結合 が支配的であると考えられる。

Table 1 に示したように，重量損失率が PLA+PMMA よ りも PLA の方が高い值を示したことから, PLA の方が PLA+PMMA よりも加水分解により樹脂が低分子化して 溶出したと考えられる。つまり, 分解抑制剤 PMMA を配 合することで, 樹脂単体の加水分解が抑制され, 繊維樹 脂界面せん断強度の低下を抑制できたものである。さら に, 加水分解は非晶領域の分解が主体的に起こることよ り ${ }^{15)}$, Fig. 5 に示したように, 結晶化度が高いと, 非晶領 域が少なくなり，加水分解が抑制されたと考えられる.

\section{4 結言}

本研究では，ガラス繊維強化ポリ乳酸複合材料のモ デルコンポジットを用いて単繊維引抜き試験を行い, 分解抑制剂の配合やアニーリング処理が繊維樹脂界面 せん断強度に及ぼす影響を明らかにするとともに, 繊維 樹脂界面せん断強度に及ぼす水環境の影響を明らかに した。 以下に得られた知見を示す.

1. 樹脂単体の吸水特性評価により求めた PLA および PLA+PMMA の重量損失率はPLA の方が PLA+PMMA よりも高く, 分解抑制剂を配合するこ とで加水分解による樹脂の溶出が抑制される.

2. 単繊維引抜き試験により求めた水環境下での繊維 樹脂界面せん断強度は, 分解抑制剤である PMMA の配合やアニーリング処理の有無に寄らず空中放 置材の試験片と比較して低い值を示したものの, 
分解抑制剂を配合し，アニーリング処理を施した GF/PLA の繊維樹脂界面せん断強度の低下率は最 も低く，優れた耐水環境特性を有する。

3. 空中放置材での繊維樹脂界面せん断強度は，マト リックスとして用いている樹脂の密度に対応して 高くなった。これは，樹脂が䋊維を締め付ける力 が繊維樹脂界面せん断強度に起因するものと考え られる。

4. 吸水材での繊維樹脂界面せん断強度の低下には, 吸水による樹脂と䋊維の化学結合の劣化が大き く影響する。分解抑制処理を行った PLA は，界面 せん断強度の低下を抑制することが出来た。

\section{参 考 文 献}

1) T. Koyanagi, "Future image of FRP industry recommendations for market expansion", Reinforced Plastics, Vol. 51, No. 12, pp.562-571 (2005).

2) J. Matsui, "Aim at environment friendly composites how to judge the propriety of composite materials recycling", Journal of the Society of Materials Science of Japan, Vol. 5, No. 11, pp.1288-1293 (2001).

3) Y. Kobayashi, "Treatment and recycling technology of FRP wastes, Journal of the Japan Society of Precision Engineering, Vol. 56, No. 4, pp.634-638 (1990).

4) K. Shibata, "FRP recycling technology", Network polymer, Vol. 28, No. 4, pp.247-256 (2007).

5) M. M. Reddy, S. Vivekanandhan, M. Misra, S. K. Bhata and A. K. Mohanty, "Biobased plastics and bionanocomposites : current status and future opportunities", Progress in Polymer Science, Vol. 38, pp.1653-1689 (2013).

6) A. A. Shah, F. Hasan, A. Hammed and S. Ahmed, "Biological degradation of plastics: a comprehensive review”, Biotechnology Advances, Vol. 26, pp.246-265 (2008).

7) H. Kawamoto, "Development in composites technology for reduction of environmental load - nanocomposite polylactic acid as a green composite", Journal of the Society of Materials Science, Japan, Vol. 57, No. 10, pp.1067-1073 (2008).

8) K. Okubo, H. Takagi and K. Goda, "Composites science/technology and new challenges for tomorrow's applications", Journal of the Society of Materials Science, Japan, Vol. 55, No. 4, pp.438-444 (2006).

9) H. Katogi, Y. Shimamura, K. Tohgo, T. Fujii and K. Takemura, "Effect of matrix properties on fatigue strength of unidirectional jute spun yarn reinforced PLA", Journal of the Society of Materials Science, Japan, Vol. 39, No. 1, pp.24-30 (2013).

10) H. Mori and H. Takagi, "Effect of molding conditions on mechanical properties of binderless bamboo fiber green composite" Transactions of the Japan Society of Mechanical Engineers, Vol. 74, No. 737, pp.84-89, (2008).

11) K. Tanaka, T. Katsura, M. Shinohara, Y. Morita, T. Katayama and K. Uno, "Heat resistant and mechanical property of jute continuous fiber reinforced PLA",
Journal of the Society of Materials Science, Japan, Vol. 59, No. 7, pp.546-552 (2010).

12) M. Murariu and P. Dibois, "The green challenge: high performance PLA (nano) composites", Jec Composites Magazine, No. 45, pp.66-69 (2008).

13) M. Tanaka, S. Abe, Y. Nohara, N. Seto, H. Saito and I. Kimpara, "Molecular simulation on effect of introduction of photo dissociable protecting groups on mechanical and hydrolysis properties of PLA", Journal of the Society of Materials Science, Japan, Vol. 42, No. 2, pp.49-58 (2016).

14) Toyo Seikan Group Holdings, Ltd, Japan Patent JP 5651932 B2.

15) M. Nishihara, S. Murase, "Hydrolysis kinetics of poly (lactic acid) fiber”, SEN'I GAKKAISHI, Vol. 59, No. 9, pp.371-374 (2003).

16) K. Komai, S. Shiroshita, S. Kinoshita and J. Grenestedt, "Influence of water on tensile and fatigue strength of angle - ply aramid/epoxy composites", Journal of the Society of Materials Science, Japan, Vol. 38, No. 434, pp.1329-1335 (1989).

17) K. Tanaka, Y. Masabe and T. Katayama, "Evaluation of interfacial properties for carbon fiber/polyamide model composites by means of single fiber pull-out test", Journal of the Society of Materials Science, Japan, Vol. 58, No. 7, pp.635-641 (2009).

18) M. Nakatani and F. Nakao, "Effect of fiber/matrix interphase on the properties of CFRP", SEN-I GAKKAISHI, Vol.44, No.2, pp.61-66 (1988).

19) K. Tanaka, N. Hosoo and T. Katayama, "Effects of temperature on the fiber matrix interfacial properties of carbon fiber reinforced highly heat resistant polyamide resin", Journal of the Society of Materials Science, Japan, Vol. 66, No. 10, pp.746-751 (2017).

20) K. Tanaka, K. Ohno and T. Katayama, "Effects of PP modification and processing time on fiber/matrix interfacial strength for carbon fiber reinforced polypropylene", WIT Transactions on the Built Environment, Vol. 166, pp.329-334 (2016).

21) Y. Hayashi and M. Kudo, "Characterization of glass surface (1) - mechanics of various surface - related phenomena on glass -", Journal of the Surface Science Society of Japan, Vol. 22, No. 1, pp.55-63 (2001).

22) M. Korn and E. Killmann, "Infrared and microcalorimetric studies of the adsorption of polymers with ester groups, in the main or side chain, at the silica/carbon tetrachloride interface", Journal of Colloid and Interface Science, Vol. 76, No. 1, pp.19-31 (1980).

23) E. Killmann, J. Eisenlauer and M. Korn, "The adsorption of macromolecules on solid/liquid interfaces", Journal of Polymer Science: Polymer Symposium, Vol. 61, No. 1, pp.413-429 (1977).

24) K. Tanaka, S. Mizuno, H. Honda, T. Katayama and S. Enoki, "Effect of water absorption on the mechanical properties of carbon fiber/polyamide composites", Journal of Solid Mechanics and Materials Engineering, Vol. 7, No. 5, pp.520-259 (2013). 